\title{
Elucidating the Surface Characteristics and Electrochemistry of High-Performance LiNiO2
}

\author{
Jing Xu, Feng Lin, Dennis Nordlund, Ethan J. Crumlin, \\ Feng Wang, Jianming Bai, Marca M. Doeff, Wei Tong
}

Accepted for Publication in Royal Society of Chemistry

January 2016

Sustainable Energy Technologies Department

Brookhaven National Laboratory

\section{U.S. Department of Energy \\ USDOE Office of Energy Efficiency and Renewable Energy (EERE), Vehicle Technologies Office (EE-3V)}




\section{DISCLAIMER}

This report was prepared as an account of work sponsored by an agency of the United States Government. Neither the United States Government nor any agency thereof, nor any of their employees, nor any of their contractors, subcontractors, or their employees, makes any warranty, express or implied, or assumes any legal liability or responsibility for the accuracy, completeness, or any third party's use or the results of such use of any information, apparatus, product, or process disclosed, or represents that its use would not infringe privately owned rights. Reference herein to any specific commercial product, process, or service by trade name, trademark, manufacturer, or otherwise, does not necessarily constitute or imply its endorsement, recommendation, or favoring by the United States Government or any agency thereof or its contractors or subcontractors. The views and opinions of authors expressed herein do not necessarily state or reflect those of the United States Government or any agency thereof. 


\section{Elucidating the Surface Characteristics and Electrochemistry of High-performance $\mathrm{LiNiO}_{2}$}

Received 00th January 20xx, Accepted 00th January $20 x x$

DOI: $10.1039 / \times 0 \times x 00000 x$
Jing $\mathrm{Xu}^{\mathrm{a}}$, Feng Lin ${ }^{\mathrm{a}}$, Dennis Nordlund ${ }^{\mathrm{b}}$, Ethan J. Crumlin ${ }^{\mathrm{c}}$, Feng Wang ${ }^{\mathrm{d}}$, Jianming Bai ${ }^{\mathrm{e}}$, Marca M. Doeff $^{\mathrm{a}}$, Wei Tong ${ }^{\mathrm{a}}$
Phase pure $\mathrm{LiNiO}_{2}$ was prepared by a solid-state method and the optimal synthesis condition led to a remarkably high capacity of $200 \mathrm{mAh} / \mathrm{g}$ with excellent retention. The combination of bulk and surface characterization elucidated an essential role of the excess $\mathrm{Li}$ in phase formation during synthesis and subsequent electrochemical performance.

At present, Li-ion batteries are considered the most promising energy storage devices for electric vehicles (EVs) and plug-in hybrid electric vehicles (HEVs). However, ultimate goals of high performance and low cost $(\$ / \mathrm{Wh})$ need to be achieved in order to replace fuel by electrical power, and realize mass adoption of $\mathrm{EVs}$ and $\mathrm{HEVs}$. $\mathrm{LiNiO}_{2}$ attracted immediate attention in the initial search for alternatives to $\mathrm{LiCoO}_{2}$ because of the isostructural characteristics and lower cost. ${ }^{1}$ Moreover, the electronic configuration of $\mathrm{Ni}^{3+}\left(3 \mathrm{~d}^{7}\right)$ in $\mathrm{LiNiO}_{2}$ allows the removal of electrons only from the $e_{g}$ band, so that loss of oxygen occurs at a lower $\mathrm{Li}$ content $\left(\mathrm{x}\right.$ in $\mathrm{Li}_{\mathrm{x}} \mathrm{MO}_{2}$ where $\mathrm{M}=\mathrm{Co}$ or $\mathrm{Ni}$ ); i.e., at a higher charge state compared to $\mathrm{LiCoO}_{2}$, which translates into higher practical capacity. ${ }^{2}$ However, because of the higher Ni content, a severe capacity fade may occur upon cycling, due to the impacts of both structural transformation and surface instability. ${ }^{3-6}$ A combination of different transition metals (e.g., $\mathrm{LiNi}_{\mathrm{x}} \mathrm{Mn}_{\mathrm{y}} \mathrm{Co}_{\mathrm{z}} \mathrm{O}_{2}$ or NMCs) further increases the complexity of the problem since phase separation and side reactions with electrolyte have been reported for different compositions. ${ }^{7,8}$ Therefore, the elucidation of the structural characteristics and their relationship with the electrochemical behavior for pure $\mathrm{LiNiO}_{2}$

\footnotetext{
${ }^{a}$ Energy Storage and Distributed Resources Division, Lawrence Berkeley Nationa Laboratory, Berkeley, CA 94720, USA Address here.

${ }^{b .}$ Stanford Synchrotron Radiation Lightsource, SLAC National Accelerator Laboratory, Menlo Park, CA 94025, USA

Advanced Light Source, Lawrence Berkeley National Laboratory, Berkeley, California 94720, USA

d. Department of Sustainable Energy Technologies, Brookhaven National Laboratory, Upton, New York 11973, USA

e. National Synchrotron Light Source II, Brookhaven National Laboratory, Upton, NY 11973, USA

†Electronic Supplementary Information (ESI) available: See DOI: $10.1039 / x 0 \times x 00000 x$
}

not only provides insights into synthesizing better performing $\mathrm{LiNiO}_{2}$ compound but also complement the mechanistic understanding for more complex R-3m layered compounds, such as nickel-rich NMC materials, by isolating synergetic effects from different transition metals.

Stoichiometric $\mathrm{LiNiO}_{2}$ is challenging to synthesize, due to the tendency for lithium loss and migration of $\mathrm{Ni}$ to the lithium layers to form off-stoichiometric $\mathrm{Li}_{1-x} \mathrm{Ni}_{1+x} \mathrm{O}_{2}$. The presence of excess $\mathrm{Ni}$ ions on the $\mathrm{Li}$ sites blocks the Li diffusion pathways and imposes a detrimental effect on the electrochemical performance. $^{9-11}$ Various conditions that are related to the synthetic routes have been explored and several key variables have been identified. For example, Ohzuku et al. investigated the effects of $\mathrm{Li}, \mathrm{Ni}$ precursors, and annealing atmosphere on the synthesis of $\mathrm{LiNiO}_{2}$ by solid state reaction and observed a pronounced effect of the $\mathrm{O}_{2}$ atmosphere on the stoichiometry and cation arrangement. ${ }^{12}$ Reacting $\mathrm{LiNO}_{3}$ with $\mathrm{Ni}(\mathrm{OH})_{2}$ or $\mathrm{NiCO}_{3}$ at $750{ }^{\circ} \mathrm{C}$ under $\mathrm{O}_{2}$ atmosphere produced a product with an initial charge capacity of $180 \mathrm{mAh} / \mathrm{g}$ and a reversible discharge capacity of above $150 \mathrm{mAh} / \mathrm{g}$ in the voltage range of 2.5 to $4.2 \mathrm{~V}\left(0.17 \mathrm{~mA} / \mathrm{cm}^{2}\right)$. Lu et al. further pointed out that high $\mathrm{O}_{2}$ partial pressure was necessary to overcome the diffusion barrier existing in the precursor powder. ${ }^{13}$ When annealed at a high $\mathrm{O}_{2}$ flow rate $(800 \mathrm{~mL} / \mathrm{min})$, the $\mathrm{LiNiO}_{2}$ product delivered a discharge capacity of $>160 \mathrm{mAh} / \mathrm{g}$ with $150 \mathrm{mAh} / \mathrm{g}$ remained after 30 cycles $\left(3.0-4.3 \mathrm{~V}, 0.4 \mathrm{~mA} / \mathrm{cm}^{2}\right) .{ }^{14}$ In addition, the Li content in the precursor also played a key role in the stoichiometry of the final product. Arai et al. reported the synthesis of a highly stoichiometric $\mathrm{LiNiO}_{2}$ obtained by mixing an aqueous solution of $\mathrm{LiOH} \cdot \mathrm{H}_{2} \mathrm{O}$ and $\mathrm{Ni}\left(\mathrm{NO}_{3}\right)_{2} \cdot 6 \mathrm{H}_{2} \mathrm{O}$ with a molar ratio of $4: 1$ and washing away the large amount of excess $\mathrm{Li}$ after calcination. This material delivered a reversible capacity of about $200 \mathrm{mAh} / \mathrm{g}$ during 10 cycles $\left(3.0-4.5 \mathrm{~V}, 0.5 \mathrm{~mA} / \mathrm{cm}^{2}\right) .{ }^{15}$ These results suggest that the design of $\mathrm{LiNiO}_{2}$ cathodes could benefit from a systematic study of the relationship between synthesis parameters, structural and chemical characteristics, and electrochemical behaviour. The need for this is reinforced by the fact that different results are obtained when nominally identical 
synthesis methods are used by different groups, owing to the complexity of controlling the $\mathrm{LiNiO}_{2}$ stoichiometry. ${ }^{16,17}$

Herein, we report a comprehensive study on the effect of various solid-state synthesis parameters on the crystal structures, morphologies, and surface characteristics of layered lithium nickel oxides and correlate these characteristics with electrochemical performance. The best $\mathrm{LiNiO}_{2}$ demonstrated excellent electrochemical performance including high discharge capacity, good rate capability, and capacity retention. The work provides insights into the surface chemistries of $\mathrm{LiNiO}_{2}$ materials and sheds lights on the design of $\mathrm{Ni}$-based cathode materials for Li-ion batteries.

$\mathrm{LiNiO}_{2}$ samples were prepared by a solid state method using both commercial and precipitated $\mathrm{Ni}(\mathrm{OH})_{2}$ precursors. The synthesis of $\mathrm{LiNiO}_{2}$ with the precipitated nickel hydroxide precursor followed the protocol originally designed for lithium nickel manganese cobalt oxide. ${ }^{4,18}$ For this, $2 \%$ and $10 \%$ excess $\mathrm{LiOH}$ precursors were used, the as-prepared samples are denoted as "solution_2exLi" and "solution_10exLi", respectively. The third sample was simply synthesized following a general solid state reaction protocol by milling $\mathrm{Li}_{2} \mathrm{CO}_{3}$ and $\mathrm{Ni}(\mathrm{OH})_{2}$ (Sigma Aldrich) precursors with $10 \%$ excess $\mathrm{Li}$, henceforth, referred to as "solid_10exLi" (for experimental details, see ESI). Figure 1 (a) shows the synchrotron X-ray diffraction (SXRD) patterns of the as-synthesized $\mathrm{LiNiO}_{2}$ powders. The high intensity ratios between $(003) /(104)$ and clear peak splits between (108) and (110) suggest good phase crystallinity and cation ordering, ${ }^{12}$ which is further confirmed by the Rietveld refinement results (Table S1). Overall, the occupancies of $3 a$ sites by $\mathrm{Ni}$ ions are less than $2 \%$ for all three samples. Scanning electron microscopy (SEM) images (Figure 1 (b) - (d)) illustrate that the secondary particle size of the assynthesized powders averages about a few microns and a relatively uniform particle size distribution was observed for the solid_10exLi sample.
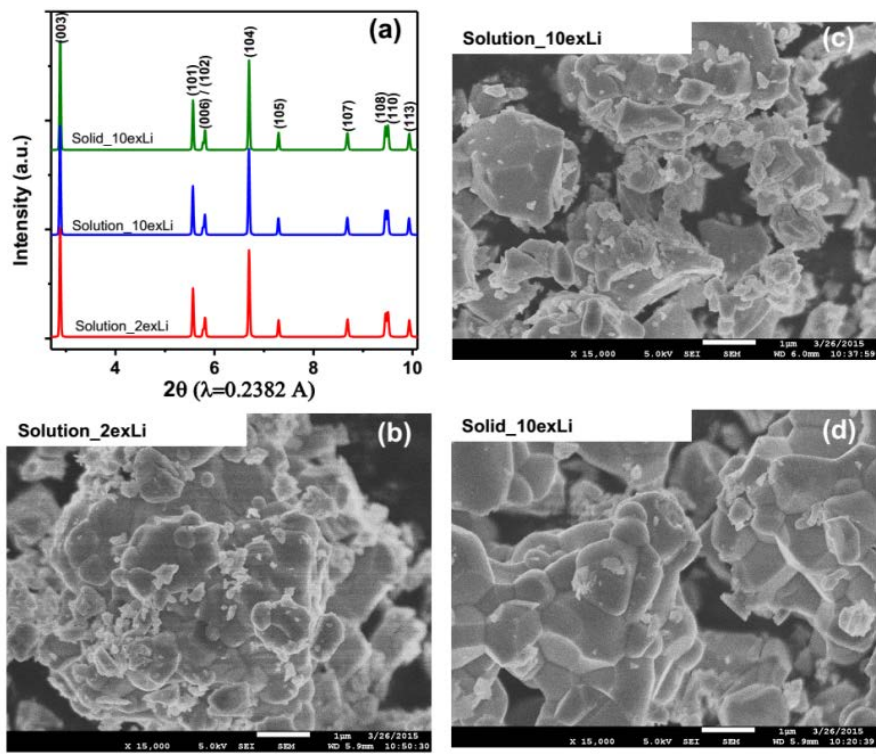

Figure 1 (a) Synchrotron X-ray diffraction patterns of $\mathrm{LiNiO}_{2}$ prepared from solution_2exLi, solution_10exLi, and solid_10exLi. (b), (c) \& (d) are SEM images of the as-prepared powders, respectively.
The materials were cycled between 4.3 and $2.7 \mathrm{~V}$ at $\mathrm{C} / 10$ for the electrochemical tests. The $1^{\text {st }}$ cycle voltage profiles are shown in Figure 2 (a). Solution_2exLi delivered a capacity of $223 \mathrm{mAh} / \mathrm{g}$ in the firstcharge, and $190 \mathrm{mAh} / \mathrm{g}$ in the first discharge. The $1^{\text {st }}$ cycle electrochemical behaviors of $\mathrm{LiNiO}_{2}$ prepared with $10 \%$ excess Li (solution_10exLi and solid_10exLi) were quite similar, suggesting negligible effect of $\mathrm{Ni}(\mathrm{OH})_{2}$ precursor. These two samples delivered a charge capacity of $240 \mathrm{mAh} / \mathrm{g}$ (corresponding to $0.85 \mathrm{Li}$ deintercalation) and a discharge capacity of $206 \mathrm{mAh} / \mathrm{g}$ (corresponding to $0.73 \mathrm{Li}$ reintercalation). These differences among the samples were repeatable and beyond what would be expected from cell-tocell variation $(<5 \mathrm{mAh} / \mathrm{g}$ ) within our experiments, and thus can be considered to result from changing the active material. The higher capacity and lower polarization for these two samples compared to those of solution_2exLi indicated that the amount of excess $\mathrm{Li}$ in the synthesis had a much larger effect on the electrochemical properties than the source of the $\mathrm{Ni}$ precursor. Not only did the larger excess of Li have positive effects on the $1^{\text {st }}$ cycle capacities, but also better rate capability and capacity retention in the subsequent cycles were observed (Figure 2 (b) and inset). After 20 cycles, 88\% discharge capacity was maintained, and the retention was still as high as $75 \%$ after 50 cycles. Such good performance has rarely been observed for $\mathrm{LiNiO}_{2}$ materials when cycled under similar conditions. In addition, both samples with $10 \%$ excess Li exhibited a good rate capability with about $90 \%$ capacity retained at $1 \mathrm{C}$. When the current density was further increased, the solid_10exLi sample delivered a slightly higher capacity than the solution_10exLi at $2 \mathrm{C}$. This is presumably due to its more uniform particle size distribution as shown by the SEM studies. In contrast, the solution_2exLi showed slightly lower discharge capacity upon cycling and in the rate test as well. Given that SXRD showed similar lattice parameters and cation ordering for these three samples (Table S1), such differences observed in the electrochemical performance of the samples synthesized with different amounts of excess $\mathrm{Li}$ and different types of $\mathrm{Ni}(\mathrm{OH})_{2}$ precursor must originate from the surface characteristics. To understand these further, surface-sensitive soft X-ray Absorption Spectroscopy (XAS) and $X$-ray Photo-electron Spectroscopy (XPS) techniques were employed.

The Ni L3-edge soft XAS spectra of the three pristine
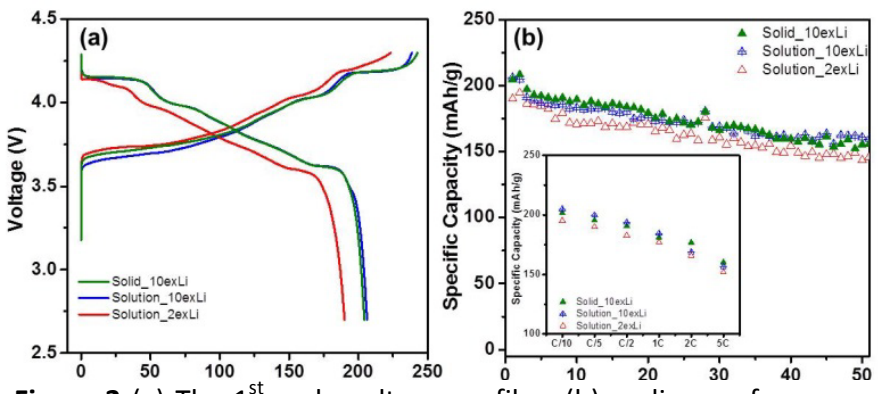

Figure 2 (a) The $1^{\text {st }}$ cycle voltage profiles, (b) cycling performances, and inset rate capabilities of solution_2exLi, solution_10exLi, and solid_10exLi. Cells were cycled between 4.3 and $2.7 \mathrm{~V}$ at $\mathrm{C} / 10$, capacity at $1 \mathrm{C}$ was defined as $180 \mathrm{mAh} / \mathrm{g}$. 
powders are shown in Figure 3 . In order to avoid contamination from the adhesive on the carbon tape, all the powders were pressed onto Au foil for characterization. Three detection modes, Auger electron yield (AEY), Total electron yield (TEY), and Fluorescence yield (FY), were collected simultaneously. Due to the different mean free paths of electrons and fluorescence in the samples, AEY, TEY and FY modes typically probe $1-2 \mathrm{~nm}, 2-5 \mathrm{~nm}$, and $\sim 50 \mathrm{~nm}$ from the sample surface towards the bulk, respectively. ${ }^{4}$ In other words, the information obtained by the soft XAS experiment on the as-prepared samples, which have a particle size of about a few microns, concerns both the surface characteristics (AEY, TEY) and the bulk (FY) of the $\mathrm{LiNiO}_{2}$ materials. For $\mathrm{LiNiO}_{2}$, the most salient electronic structure can be qualitatively obtained through the deconvolution of the Ni L3-edge into high-energy $\left(L 3_{\text {high }}\right)$ and low-energy ( $\left.L 3_{\text {low }}\right)$ features. The ratio between $\mathrm{L} 3_{\text {high }}$ and $\mathrm{L} 3_{\text {low }}$ is in a positive relationship with $\mathrm{Ni}$ oxidation state. The three modes (AEY, TEY, and FY) of Ni L3-edge for each sample shown in Figure 3 (a) are normalized with respect to the $\mathrm{L} 3_{\text {low }}$ feature. It can be clearly seen that the variation in the $\mathrm{Ni}$ oxidation state follows a similar trend from the very surface to the sub-surface for all three of the samples. As evidenced by the increased $\mathrm{L} 3_{\text {high }} / \mathrm{L} 3_{\text {low }}$ ratios from $A E Y$ to $F Y$ mode, $\mathrm{Ni}$ is more oxidized in the sub-surface region of the $\mathrm{LiNiO}_{2}$ samples compared to their surfaces; in other words, there is an oxidation state gradient. When comparing each mode across the three samples (Figure 3 (b)), it can be seen

(a)



(b)



Figure 3 Soft XAS spectra for the three pristine $\mathrm{LiNiO}_{2}$ samples. (a) $\mathrm{Ni}$ L3-edge spectra from three detection modes with different probing depths (AEY: 1 - 2 nm; TEY: 2 - 5 nm; FY: $50 \mathrm{~nm}$ ). Note: all the spectra are normalized with respect to the low energy $\mathrm{Ni}$ $\mathrm{L} 3$-edge, denoted as $\mathrm{L} 3_{\text {low }}$. (b) $\mathrm{L} 3_{\text {high }} / \mathrm{L} 3_{\text {low }}$ ratios of all three samples at different modes shown in (a). that the solution_2exLi has the lowest $\mathrm{Ni}$ oxidation state in all three modes, while the $\mathrm{L} 3_{\text {high }} / \mathrm{L} 3_{\text {low }}$ ratios for the other two samples with $10 \%$ excess $\mathrm{Li}$ are very close to each other, indicating similar $\mathrm{Ni}$ oxidation states and gradients.

In addition to the study on $\mathrm{Ni}$ oxidation state by soft XAS, XPS was also employed to further investigate the surface properties. As can be seen in Figure 4 (a), the main feature of the 01s XPS regions for all three samples is one strong peak around $531.5 \mathrm{eV}$, which is associated with $\mathrm{Li}_{2} \mathrm{CO}_{3}$ on the surfaces. ${ }^{19,20}$ The presence of surface $\mathrm{Li}_{2} \mathrm{CO}_{3}$ is also supported by the following observations: (1) the Li1s peak located at 55.5 $\mathrm{eV}$ in Figure 4 (b), (2) the C1s peak around $290 \mathrm{eV}$ in the XPS (Figure S1). ${ }^{19,}{ }^{20}$ Close examination of the XPS spectra shows the presence of a small peak with very low intensity at 529.5 eV in the solution_2exLi and solid_10exLi samples (Figure 4 (a)) which can be ascribed to $O$ in oxide, in this case the lattice of the active material. ${ }^{19,20}$ The low intensity of the oxide peak indicate that the reaction layer at the surface is a few $\mathrm{nm}$ (The O1s XPS was recorded at $670 \mathrm{eV}$, resulting in a very surface sensitive mean free path of less than $1 \mathrm{~nm}$ ). The peak is almost invisible in the XPS spectra of solution_10exLi sample (Figure 4 (a)). In Figure 4 (b), the Li1s and Ni3p XPS region is plotted across the same three samples, and normalized to the Li1s peak intensity. We find a positive correlation between the intensities of $01 \mathrm{~s}$ peaks corresponding to oxygen in the lattice $(529.5 \mathrm{eV})$ and those due to Ni3p $(67.6 \mathrm{eV})$. The solution_10exLi sample exhibits the lowest intensity Ni3p peak while the $01 \mathrm{~s}$ in the lattice is almost invisible (Figure 4 (a)). In addition, despite the cross-section difference between Li1s and Ni3p at $670 \mathrm{eV}$ excitation, ${ }^{21}$ we would expect to see the typical peak of Li1s at about $53.6 \mathrm{eV}$ associated with the $\mathrm{Li}$ in the lattice; ${ }^{22}$ however, it is missing in all of the three samples. This directly suggests that the surface $\mathrm{Ni}$ atoms exist in a NiOtype phase instead of in layered $\mathrm{LiNiO}_{2}$. In fact, surface NiOtype phase formation in the solution_2exLi sample is correlated with the lower valance state of $\mathrm{Ni}$ observed by the soft SXAS experiments because $\mathrm{Ni}$ in $\mathrm{NiO}$ phase is expected to be divalent, whereas it is trivalent in pristine $\mathrm{LiNiO}_{2}$. The combination of XPS and soft XAS results leads to the conclusion that $\mathrm{Li}_{2} \mathrm{CO}_{3}$ seems to inevitably form on the surface of $\mathrm{LiNiO}_{2}$ even when the amount of excess lithium-containing precursor is small (2\%). The lower amount of lithium-excess
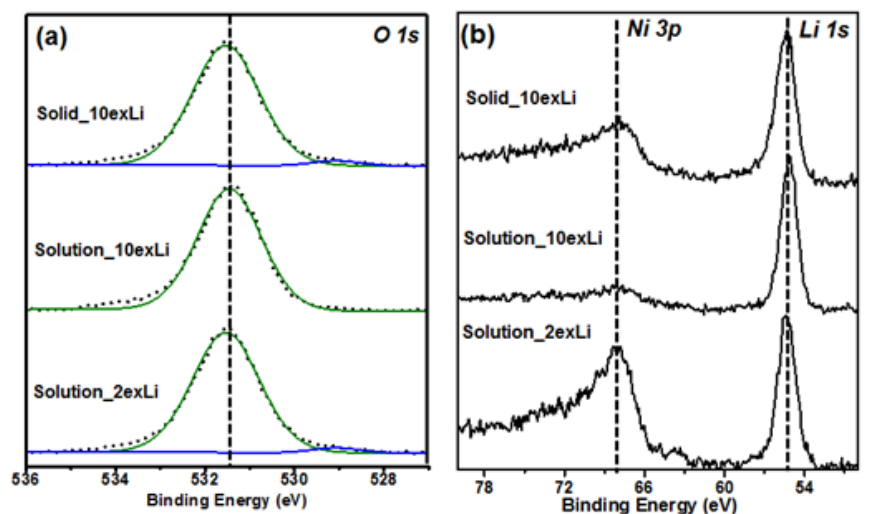

Figure 4 XPS (a) O1s regions and (b) Ni3p / Li1s regions for pristine solution_2exLi, solution_10exLi, and solid_10exLi, respectively. Dash and solid lines in (a) indicate observed and fitted profiles. 
also results in a stronger tendency to form reduced $\mathrm{Ni}$ on particle surfaces, probably in the form of a rock salt phase related to $\mathrm{NiO}$. The main role of a sufficiently large Li-excess during solid-state synthesis appears to be in the suppression of NiO-type phase formation containing divalent nickel on particle surfaces, which can impede lithium diffusion during cycling, resulting in inferior electrochemical behavior. The effects of the amount of lithium excess during $\mathrm{LiNiO}_{2}$ synthesis are subtle, affecting primarily the particle surfaces rather than the bulk, which can explain previous results in samples that appear to have similar bulk properties perform differently.

In summary, stoichiometric $\mathrm{LiNiO}_{2}$ with excellent electrochemical performance was successfully synthesized by a solid-state method. The synchrotron XRD results proved that all of the as-prepared $\mathrm{LiNiO}_{2}$ bulk samples were highly crystalline and phase-pure with few defects $(<2 \% \mathrm{Ni}$ in $3 a$ sites) no matter how much excess lithium was used or what the source of the $\mathrm{Ni}(\mathrm{OH})_{2}$ starting materials were. However, soft XAS showed that, while $\mathrm{Ni}$ tended to be more reduced on the surfaces of all the samples, those made with a higher amount of excess $\mathrm{Li}(10 \%)$ were less extreme in this regard compared to a sample made with only a $2 \%$ excess. This information, in combination with the Li1s, Ni3p, and O1s XPS spectra, can be interpreted to mean that $\mathrm{Ni}$ on the surface exists in the form of a NiO-type phase, particularly for the sample made with only a $2 \%$ excess of lithium. The XPS O1s and $\mathrm{C} 1 \mathrm{~s}$ spectra also revealed that $\mathrm{Li}_{2} \mathrm{CO}_{3}$ preferably formed on the surface of the particles during synthesis even for samples made with a low amount of excess lithium. Both XPS and soft XAS results confirmed the possible formation of NiO-type phase on the surface, which is inversely correlated to the amount of surface $\mathrm{Li}_{2} \mathrm{CO}_{3}$ formation. The results indicate that the amount of $\mathrm{NiO}$ on the surface can be reduced (although not eliminated entirely) by using a sufficient excess of $L i$ in the synthesis. This study shows a direct correlation between the surface characteristics and superior electrochemical performance, both of which are largely influenced by the amount of excess $\mathrm{Li}$ used in the synthesis and explains why samples with similar bulk properties perform differently. This may also have implications for the syntheses and optimization of other $\mathrm{Ni}$-rich layered oxide cathode materials (e.g., $\mathrm{LiNi}_{\mathrm{x}} \mathrm{Co}_{y} \mathrm{Al}_{1-\mathrm{x}-\mathrm{y}} \mathrm{O}_{2}$ and $\mathrm{LiNi}_{\mathrm{x}} \mathrm{Mn}_{\mathrm{y}} \mathrm{Co}_{1-\mathrm{x}-\mathrm{y}} \mathrm{O}_{2}(0<\mathrm{x}, \mathrm{y}<1)$ ) of interest for battery applications.

This work was supported by the Assistant Secretary for Energy Efficiency and Renewable Energy, Office of Vehicle Technologies of the U.S. Department of Energy (DOE) under Contract No. DE-AC02-05CH11231. Soft XAS experiments were carried out at the Stanford Synchrotron Radiation Lightsource, a Directorate of SLAC National Accelerator Laboratory and an Office of Science User Facility operated for the U.S. DOE Office of Science by Stanford University. Use of the Stanford Synchrotron Radiation Lightsource, SLAC National Accelerator Laboratory, is supported by the U.S. DOE, Office of Science, Office of Basic Energy Sciences under Contract No. DE-ACO276SF00515. J. Bai and F. Wang thank the support by the U.S. DOE Office of Energy Efficiency and Renewable Energy under the Advanced Battery Materials Research (BMR) program,
Contract No. DE-SC0012704. Use of the National Synchrotron Light Source II, Brookhaven National Laboratory, was supported by the U.S. DOE, Office of Science, Office of Basic Energy Sciences, under Contract No. DE-SC0012704. Synchrotron XPS was carried out at beamline 9.3.2 at the Advanced Light Source in Lawrence Berkeley National Laboratory, which is supported by the Director Office of Science, Office of Basic Energy Sciences, of the U.S. DOE under Contract No. DE-ACO2-05CH11231.

\section{References}

1. A. Kraytsberg and Y. Ein-Eli, Advanced Energy Materials, 2012, 2, 922-939.

2. R. V. Chebiam, F. Prado and A. Manthiram, Chemistry of Materials, 2001, 13, 2951-2957.

3. F. Lin, D. Nordlund, I. M. Markus, T.-C. Weng, H. L. Xin and M. M. Doeff, Energy \& Environmental Science, 2014, 7, 3077-3085.

4. F. Lin, I. M. Markus, D. Nordlund, T.-C. Weng, M. D. Asta, H. L. Xin and M. M. Doeff, Nature Communications, 2014, 5.

5. H.-J. Noh, S. Youn, C. S. Yoon and Y.-K. Sun, Journal of Power Sources, 2013, 233, 121-130.

6. Y.-K. Sun, D.-J. Lee, Y. J. Lee, Z. Chen and S.-T. Myung, ACS Applied Materials \& Interfaces, 2013, 5, 11434-11440.

7. J. M. Zheng, W. H. Kan and A. Manthiram, Acs Applied Materials \& Interfaces, 2015, 7, 6926-6934.

8. P. F. Yan, J. M. Zheng, D. P. Lv, Y. Wei, J. X. Zheng, Z. G. Wang, S. Kuppan, J. G. Yu, L. L. Luo, D. Edwards, M. Olszta, K. Amine, J. Liu, J. Xiao, F. Pan, G. Y. Chen, J. G. Zhang and C. M. Wang, Chemistry of Materials, 2015, 27, 5393-5401.

9. B. L. Ellis, K. T. Lee and L. F. Nazar, Chemistry of Materials, 2010, 22, 691-714.

10. C. Li, H. P. Zhang, L. J. Fu, H. Liu, Y. P. Wu, E. Ram, R. Holze and H. Q. Wu, Electrochimica Acta, 2006, 51, 3872-3883.

11. A. Rougier, P. Gravereau and C. Delmas, Journal of the Electrochemical Society, 1996, 143, 1168-1175.

12. T. Ohzuku, A. Ueda and M. Nagayama, Journal of the Electrochemical Society, 1993, 140, 1862-1870.

13. C. H. Lu and L. Wei-Cheng, Journal of Materials Chemistry, 2000, 10, 1403-1407.

14. K. S. Park, S. H. Park, Y. K. Sun, K. S. Nahm, Y. S. Lee and M. Yoshio, Journal of Applied Electrochemistry, 2002, 32, 12291233.

15. H. Arai, S. Okada, H. Ohtsuka, M. Ichimura and J. Yamaki, Solid State lonics, 1995, 80, 261-269.

16. T. Ohzuku, A. Ueda and M. Nagayama, Journal of The Electrochemical Society, 1993, 140, 1862-1870.

17. A. Rougier, P. Gravereau and C. Delmas, Journal of The Electrochemical Society, 1996, 143, 1168-1175.

18. F. Lin, D. Nordlund, T. Pan, I. M. Markus, T.-C. Weng, H. L. Xin and M. M. Doeff, Journal of Materials Chemistry A, 2014, 2, 19833-19840.

19. A. M. Andersson, D. P. Abraham, R. Haasch, S. MacLaren, J. Liu and K. Amine, Journal of the Electrochemical Society, 2002, 149, A1358-A1369.

20. N. Yabuuchi, K. Yoshii, S. T. Myung, I. Nakai and S. Komaba, Journal of the American Chemical Society, 2011, 133, 44044419.

21. J. J. Yeh and I. Lindau, Atomic Data and Nuclear Data Tables, 1985, 32, 1-155.

22. M. Oku, H. Tokuda and K. Hirokawa, Journal of Electron Spectroscopy and Related Phenomena, 1991, 53, 201-211. 


\section{Electronic Supplementary Information}

\section{Elucidating the Surface Characteristics and Electrochemistry of High-performance $\mathrm{LiNiO}_{2}$}

Jing $\mathrm{Xu}^{\mathrm{a}}$, Feng Lin ${ }^{\mathrm{a}}$, Dennis Nordlund ${ }^{\mathrm{b}}$, Ethan J. Crumlin ${ }^{\mathrm{c}}$, Feng Wang ${ }^{\mathrm{d}}$, Jianming Bai ${ }^{\mathrm{e}}$, Marca M. Doeff ${ }^{a}$, Wei Tong ${ }^{a}$

${ }^{a}$ Energy Storage and Distributed Resources Division, Lawrence Berkeley National Laboratory, Berkeley, CA 94720, USA

${ }^{b}$ Stanford Synchrotron Radiation Lightsource, SLAC National Accelerator Laboratory, Menlo Park, CA 94025, USA

${ }^{c}$ Advanced Light Source, Lawrence Berkeley National Laboratory, Berkeley, California 94720, USA

${ }^{d}$ Department of Sustainable Energy Technologies, Brookhaven National Laboratory, Upton, New York 11973, USA

${ }^{e}$ National Synchrotron Light Source II, Brookhaven National Laboratory, Upton, NY 11973, USA 
Table S1. Refinement results based on Synchrotron XRD of $\mathrm{LiNiO}_{2}$.

\begin{tabular}{cccc}
\hline Sample & $\begin{array}{c}\text { Lattice } \\
\text { Parameter }(\mathbf{A})\end{array}$ & $\begin{array}{c}\text { Ni on 3a } \\
\text { site (\%) }\end{array}$ & $\begin{array}{c}\text { R value } \\
(\%)\end{array}$ \\
\hline Solid_10exLi & $\begin{array}{c}a=2.875 \\
\mathrm{c}=14.197\end{array}$ & 1.44 & 3.02 \\
Solution_10exLi & $\begin{array}{c}\mathrm{a}=2.874 \\
\mathrm{c}=14.190\end{array}$ & 1.03 & 3.09 \\
Solution_2exLi & $\begin{array}{c}\mathrm{a}=2.874 \\
\mathrm{c}=14.188\end{array}$ & 1.08 & 3.12 \\
\hline
\end{tabular}



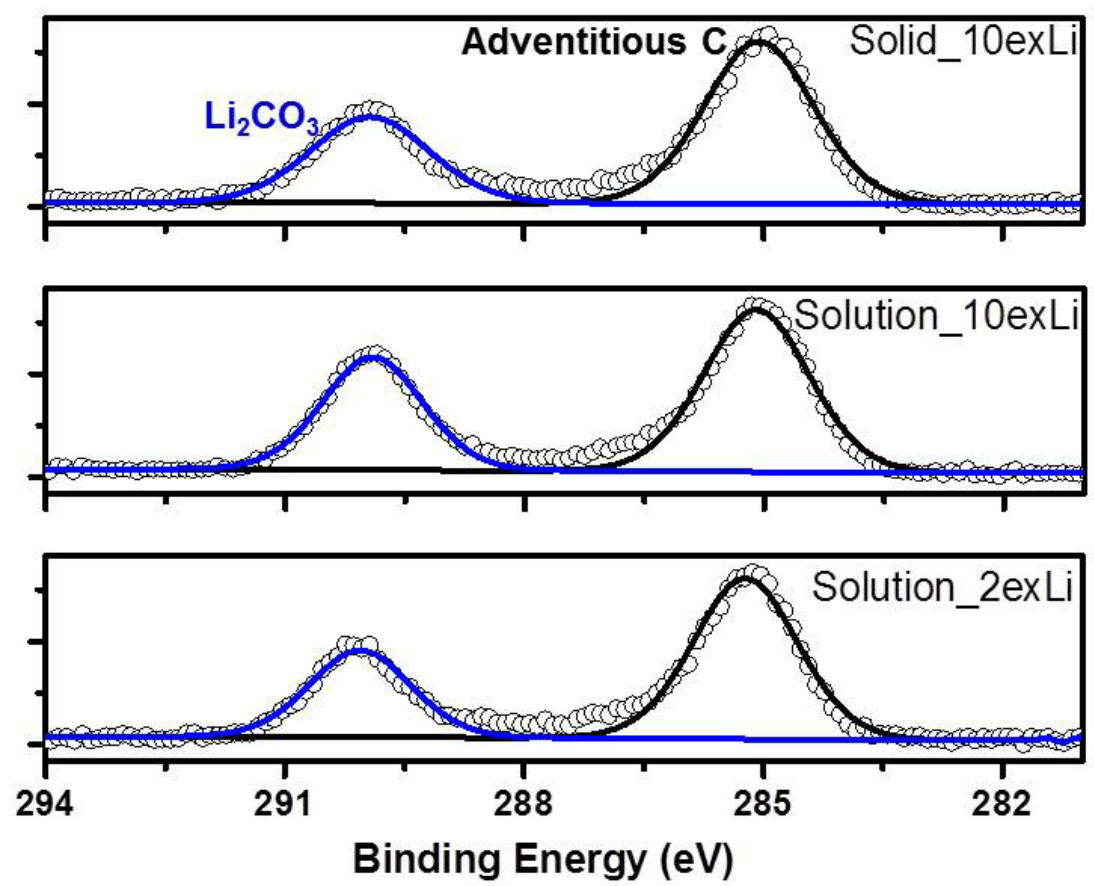

Figure S1. XPS C 1s regions of (a) Solution_2exLi, (b) Solution_10exLi, and (c) Solid_10exLi, respectively. Open circles and lines indicate observed and fitted profiles. The peak at $285.0 \mathrm{eV}$ (black curve) is the photoemission of adventitious hydrocarbons, and the peak at $\sim 290 \mathrm{eV}$ (blue curve) results from surface carbonate groups. 


\section{Experimental}

$\mathrm{Ni}(\mathrm{OH})_{2}$ precursors used for the Solution_10ex and Solution_2ex samples were prepared by a precipitation method. $\mathrm{Ni}\left(\mathrm{NO}_{3}\right)_{2} \cdot 6 \mathrm{H}_{2} \mathrm{O}$ (Sigma Aldrich) was dissolved in de-ionized (DI) water $(0.4 \mathrm{M})$ and then slowly dripped into a LiOH (Sigma Aldrich, 0.8 M) solution using a masterflex C/L peristaltic pump and stirred continuously. The precipitate was collected, filtered and washed with deionized water, and then dried overnight at $100 \square \mathrm{C}$ in the oven. The dried precipitate was high energy milled (500 rpm, 1h) with $\mathrm{LiOH}$, where $10 \%$ excess $\mathrm{Li}$ and 2\% excess Li was added for the samples Solution_10ex and Solution_2ex, respectively. The ball-milled mixture was then annealed in $\mathrm{O}_{2}$ (5 cft) at $750 \square \mathrm{C}$ for $12 \mathrm{~h}$. Solid_10exLi sample was prepared by ball milling $\mathrm{Li}_{2} \mathrm{CO}_{3}$ (Sigma Aldrich) and $\mathrm{Ni}(\mathrm{OH})_{2}$ (Sigma Aldrich) at $500 \mathrm{rpm}$ for $12 \mathrm{~h}$ (Retsch, PM100) and then annealing at $750 \square \mathrm{C}$ for $12 \mathrm{~h}$ under $\mathrm{O}_{2}$ flow.

Scanning electron microscopy (SEM) was performed on a JEOL JSM-7000F equipped with a Thermo Scientific EDS (energy dispersive X-ray spectroscopy) detector. The XAS measurements were carried out on beamline 8-2 at the Stanford Synchrotron Radiation Laboratory and were conducted on powder samples, which were pressed on Au foil to avoid contamination from the adhesive of the carbon tape. Data were acquired under ultrahigh vacuum $\left(10^{-9}\right.$ Torr) in a single load at room temperature using total electron yield (TEY) via the drain current, Auger electron yield (AEY) via a Cylindrical Mirror Analyzer, and fluorescence yield (FY) modes via a Silicon Photodiodes. The XPS experiments were performed with an incident phonon energy of $670 \mathrm{eV}$ at beamline 9.3.2 at the Advanced Light Source in Lawrence Berkeley National Laboratory using a Scienta 4000R analyzer operated with Pass Energy of $100 \mathrm{eV}$ (total energy resolution of $0.1 \mathrm{eV}$ ). The spectra were calibrated to the C1s photoemission peak of adventitious hydrocarbons at $285.0 \mathrm{eV}$.

Electrodes were prepared from slurries containing $80 \mathrm{wt} \%$ of active material, $10 \mathrm{wt} \%$ of polyvinylidene fluoride (PVdF) as a binder, and $10 \mathrm{wt} \%$ acetylene carbon black (Denka, 50\% compressed) in N-methylpyrrolidone (NMP). The slurries were then casted on carbon-coated aluminum current collectors (Exopack Advanced Coatings) using a doctor blade set to $75 \mu \mathrm{m}$ height and then dried under vacuum at $120 \square \mathrm{C}$ to form electrodes. Typical loadings of the active materials were around $2.5 \mathrm{mg} / \mathrm{cm}^{2}$. 2032-type coin cells were assembled in an Ar-filled glove box $\left(\mathrm{H}_{2} \mathrm{O}<0.1 \mathrm{ppm}\right)$ with $\mathrm{Li}$ metal as the negative electrode. A Celgard 2400 separator 
and $1 \mathrm{M} \mathrm{LiPF}_{6}$ electrolyte solution in 1:2 w/w ethylene carbonate - diethyl carbonate (Ferro Corporation) were used to fabricate the cells. Galvanostatic discharge and charge at various current densities between $4.3 \mathrm{~V}$ and $2.7 \mathrm{~V}$ were performed on a Maccor 4200 battery cycler. $1 \mathrm{C}$ was defined as $180 \mathrm{~mA} \mathrm{~g}^{-1}$ for this work. 